\title{
SIMULASI ANGGARAN DAYA SISTEM KOMUNIKASI SERAT OPTIK BERBASIS MATLAB 7.5
}

\section{SIMULATION OF OPTICAL FIBER POWER BUDGET COMMUNICATION SYSTEMS BASED MATLAB 7.5}

\author{
Lucia Jambola \\ Institut Teknologi Nasional Bandung \\ PKH. Hasan Mustapha no. 23 Bandung \\ shafihazidrahman@gmail.com
}

\begin{abstract}
Abstrak
Berkembangnya dunia telekomunikasi membuat kebutuhan akan media transmisi yang dapat menyalurkan informasi dengan kecepatan tinggi, memiliki kapasitas besar dan handal semakin dibutuhkan. Penggunaan kabel serat optik sebagai media transmisi dalam dunia telekomunikasi merupakan salah satu solusi dari berbagai permasalahan diatas. Serat optik mampu meningkatkan pelayanan sistem komunikasi data, suara dan video seperti peningkatan kanal yang tersedia.Sebelum serat optik digunakan dalam sebuah jaringan telekomunikasi perlu dilakukan suatu perhitungan dan analisis anggaran daya untuk mengetahui kualitas, biaya, kelayakan sistem dan kebutuhan komponen Erbium Dopped Fiber Amplifier (EDFA) sehingga sistem komunikasi serat optik tersebut dapat berjalan dengan baik. Pengujian yang dilakukan adalah menghitung anggaran daya pada system komukasi serat optik Bandung - Garut tanpa menggunakan penguat EDFA serta menggunakan penguat EDFA. Untuk mempermudah perencanaan sistem komunikasi serat optik diperlukan simulasi perhitungan anggaran daya menggunakan GUI MATLAB 7.5.
\end{abstract}

Kata kunci : anggaran daya, EDFA, kelayakan sistem

\begin{abstract}
The development of telecommunications world makes the need for a transmission medium that can distribute information at high speed, has a large capacity and reliable increasingly needed. The use of fiber-optic cable as a transmission medium in the world of telecommunications is one of the solutions to the above problems. Optical fiber communication system to improve services of data, voice and video as the increase of available channels.Before the optical fibers are used in a telecommunications network needs to do a computation and power budget analysis to determine the quality, cost, feasibility of the system and the component needs dopped Erbium Fiber Amplifiers (EDFA) so that the optical fiber communication system can work well. Testing is done is calculate the power budget in a fiber optic system commucation Bandung Garut without using EDFA amplifier and using EDFA amplifier. To facilitate the planning of optical fiber communication systems, the required power budget calculation simulation using MATLAB 7.5 GUI.
\end{abstract}

Keywords: power budget, EDFA, the feasibility of the system 


\section{PENDAHULUAN}

Penggunaan kabel serat optik sebagai media transmisi dalam bidang telekomunikasi telah memberikan berbagai keuntungan dan manfaat baik dari segi transfer data maupun dari segi ekonomi karena dapat mengurangi penggunaan banyak kabel. Dalam merencanakan suatu jaringan SKSO diperlukan power link budgetuntukmenganalisa kelayakan suatu SKS.Perhitungan serta analisis power link budgetdilakukan untuk mengetahui kualitas suatu jaringan, biaya, serta mengetahui kelayakan suatu jaringan.Untuk mempermudah pengelola dalam merencanakan dan merancang sistem komunikasi serat optik diperlukan simulasi perhitungan dan analisis simulasi optical power link budget Tujuan dari penelitian ini adalah membuat program simulasi untuk mempermudah pengguna untuk menghitung power link budget menggunakan GUI Matlab 7.5 dan menganalisis kelayakan SKSO berdasarkan simulasi power link budget.

\section{TEORI dan METODOLOGI}

\subsection{Sistem Komunikasi Serat Optik [1]}

Sistem komunikasi serat optik adalah pengiriman sinyal informasi dalam bentuk sinyal cahaya dari bagian pemancar ke penerima.Proses pengiriman sinyal informasi yang melalui serat optik adalah menggunakan prinsip pemantulan sinyal optik yang berupa cahaya dengan panjang gelombang tertentu. Secara umum konfigurasi sistem komunikasi serat optik ditunjukkan pada Gambar 1 di bawah ini.

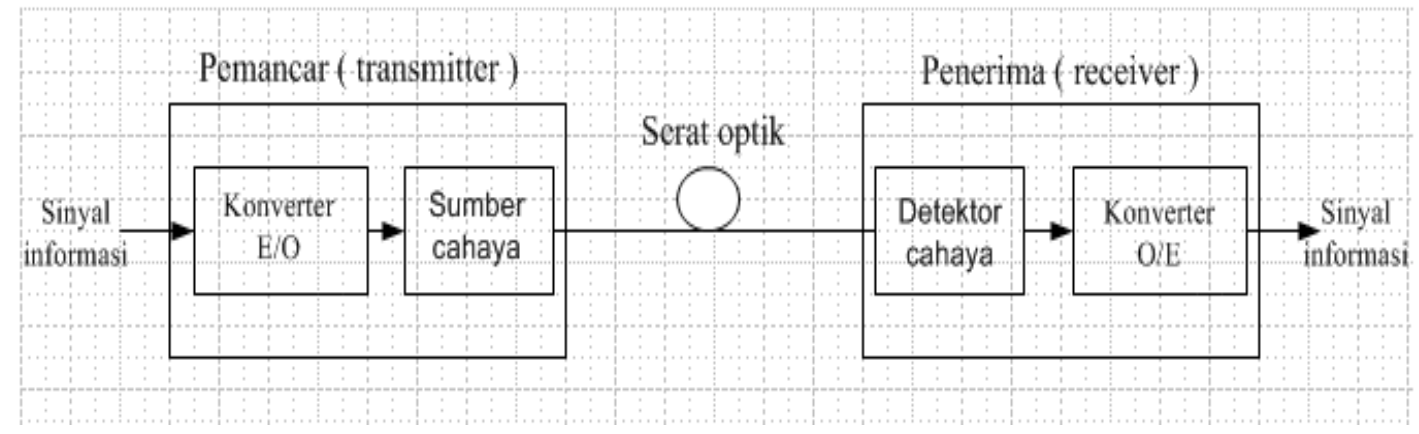

Gambar 1. Konfigurasi Sistem Komunikasi Serat Optik

Pemancar berfungsi mengubah sinyal elektrik ke dalam sinyal cahaya, kabel serat optik berfungsi sebagai media transmisi dan penerima berfungsi mengubah sinyal cahaya yang diterima menjadi sinyal elektrik.

Berdasarkan Gambar 1 diatas dapat dilihat bahwa komponen dari SKSO terdiri dari :

a. Sumber cahaya

Sumber cahaya berfungsi mengubah sinyal elektrik menjadi sinyal cahaya (E/O converter), kriteria yang harus dipenuhi sumber cahaya adalah ukuran dan konfigurasi yang sesuai dengan cahaya yang masuk kedalam serat optik, mempunyai akurasi yang tinggi, cahaya yang dihasilkan dapat digandeng ke serat optik sehingga menghasilkan daya optik yang cukup, menghasilkan cahaya dengan lebar pita yang cukup sempit untuk meminimumkan efek dispersi.

Ada dua macam sumber cahayayang sering diaplikasikan, pemakaian kedua jenis sumber optik ini tergantung dari pada bit rate transmisi data dan jarak tempuh yang ingin dicapai , kedua jenis sumber cahaya ini adalah :

1. LED ( Light emmiting diode )

2. LASER ( Light Amplification by Stimulated Emmission of Radiation ) 
b. Detektor Cahaya

Setelah cahaya tiba di sisi penerima ( receiver ), cahaya yang dipancarkan dari ujung link serat optik harus dideteksi dan dikonversikan ke dalam pulsa-pulsa elektronik untuk pemrosesan lebih jauh sehingga informasi yang ditransmisikan dapat diterima. Jenis detektor optik yang digunakan pada sisi penerima yaitu :

1. APD ( Avalance Photo Diode)

2. PIN ( Positive Instrinsic Negative Photo Diode)

c. Serat Optik

Serat optik dikarakteristikan oleh strukturnya dan sifat transmisinya. Secara dasar, serat optik diklasifikasikan menjadi dua

1. Serat Optik Single Mode

2. Serat Optik Multi Mode

\subsection{Redaman Serat Optik [2]}

Redaman yang terjadi pada SKSO dapat diakibatkan redaman serat optik, sambungan (splice), konektor, semakin besar jumlah redaman akan semakin sedikit cahaya yang dapat mencapai detektor optik, sehingga akan semakin dekat jarak antara penguat sinyal optik.

1. Redaman serat optik ( Attentuationloss)

Redaman dalam serat optik, juga dikenal sebagai kerugian transmisi, adalah pengurangan intensitas berkas cahaya (atau sinyal) sehubungan dengan jarak tempuh melalui media transmisi. Satuan dalam redaman serat optik adalah satuan dB / $\mathrm{km}$. Penelitian empiris menunjukkan bahwa redaman serat optik disebabkan terutama oleh hamburan rayleighdan penyerapan . Redaman serat optik bergantung pada panjang gelombang yang akan digunakan.

2. Redaman penyambungan ( splice loss )

Redaman penyambungan yang terjadi akibat adanya penyambungan dari dua buah kabel serat optik.

3. Redaman konektor ( connector loss )

Penyambungan serat optik menggunakan konektor bersifat tidak permanen, artinya dapat dibongkar pasang. Konektor biasanya digunakan untuk kontak dengan terminal perangkat aktif seperti penguat. Dengan adanya pemasangan konektor maka akan menambah nilai redaman pada SKSO.

4. Redaman lainnya ( other fiber loss )

Redaman serat optik ini biasanya diakibatkan oleh pembengkokan akibat adanya pancaran atau hamburan Rayleigh yang terjadi pada kabel serat optik.

\subsection{Penguat Optik ( Optical Amplifier ) [1]}

Erbium Dopped Fiber Amplifier (EDFA) merupakan penguat optik yang intinya dikotori oleh atom erbium sehingga dapat memberikan penguatan terhadap sinyal yang melewatinya.EDFA akan memperkuat sinyal cahaya disekitar panjang gelombang 1.55 $\mu \mathrm{m}$.EDFA ditempatkan dalam suatu modul yang terdiri dari komponen-komponen pendukung untuk memberikan kinerja terbaik kepada sistem secara keseluruhan.

\subsection{WDM ( Wavelength Division Multiplexing )}

Teknologi WDM pada dasarnya adalah teknologi transportasi untuk menyalurkan berbagai jenis trafik (data, suara, dan video) secara transparan, dengan menggunakan panjang gelombang yang berbeda-beda dalam suatu fiber tunggal secara bersamaan. Implementasi 
WDM dapat diterapkan baik pada jaringan long haul (jarak jauh) maupun untuk aplikasi short haul (jarak dekat). Gambar 2.14 menunjukan karakteristik sistem kerja dari WDM. Karakteristik sistem kerja WDM yaitu memonitor beberapa protocol, dengan spasi kanal 50GHz, 100GHz, $200 \mathrm{GHz}$, sesuai dengan seberapa banyak dan jenis apa yang digunakan. Kapasitasnya yaitu sebesar : $1.25 \mathrm{~Gb} / \mathrm{s}, 2.5 \mathrm{~Gb} / \mathrm{s}, 10 \mathrm{~Gb} / \mathrm{s}$.

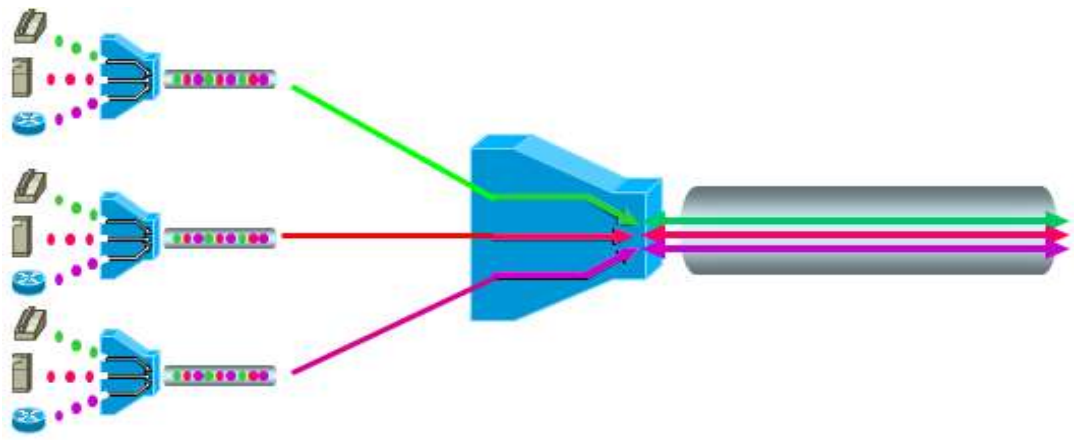

Gambar 2. Sistem Kerja dari WDM

\subsection{Dispersi}

Peristiwa dispersi serat optik disebabkan oleh melebarnya pulsa yang dipancarkan dan merambat sepanjang serat optik. Pulsa yang melebar akan saling menumpuk sehingga menjadi tidak bisa dibedakan pada input penerima. Efek ini dikenal dengan inter symbol interference( ISI ). Dispersi sinyal akan membatasi lebar pita ( bandwidth) maksimum yang dapat dicapai agar masing-masing symbol masih dapat dibedakan. Dalam serat optik terdapat macam-macam dispersi yaitu :

1. Dispersi intermodal

Dispersi intermodal adalah pelebaran pulsa sebagai akibat dari perbedaan delay propagasi antara satu mode dengan mode penjalaran lainnya.

2. Dispersi Intramodal

Dispersi intramodal sering disebut dispersi kromatik ( chromatic dispertion). Serat optik single mode mempunyai keuntungan dimana dispersi yang terjadi hanya dispersi intramodal karena merambat hanya terdapat satu mode. Dispersi ini disebut juga dispersi material yang terjadi karena indeks bias bervariasi sebagai fungsi yang tidak linear dari panjang gelombang optik.

3. Dispersi Mode Polarisari (Polarization mode dispersion )

Dispersi mode polarisasi (PMD) adalah suatu dispersi mode polarisasi yang ada pada serat single mode atau komponen optik di mana pulsa penyebarannya disebabkan oleh kecepatan propagasi yang berbeda dari dua sinyal polarisasi ortogonal.

\subsection{Anggaran Daya Sistem Komunikasi Serat Optik [3]}

Power link budgetdalam komunikasi serat optik adalah daya yang tersedia di pengirim (Ptx) pada komunikasi serat optik yang disesuaikan dan dialokasikan dengan kerugian seperti rugi penyambungan (splice), redaman serat, rugi konektor, rugi-rugi lainnya serta penguat (EDFA) untuk memastikan bahwa kekuatan daya sinyal (Prx) tersedia cukup pada penerima agar sistem tersebut layak.

Power link budget biasanya ditentukan atau dinyatakan dalam desibel (dB).Produsen biasanya menentukan power link budget hanya untuk serat yang optimal untuk peralatan mereka atau hanya menentukan bahwa peralatan mereka akan beroperasi atas jarak tertentu, tanpa 
menyebutkan karakteristik serat optik atau parameter-parameter desain yang ada pada komunikasi serat optik. Gambar 3di bawah ini merupakan blok diagram power link budget.

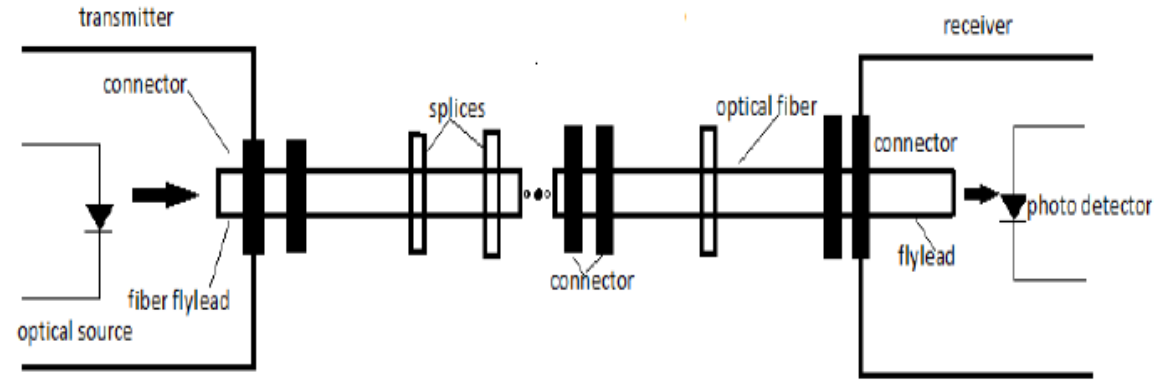

Gambar 3. Blok Diagram Power Link Budget

Adapun parameter yang digunakan dalam simulasi power link budget Sistem Komunikasi Serat Optik adalah sebagai berikut :

1. Redaman dari yang terjadi pada SKSO [5]

$t_{l f}=\left(l_{a} x L\right)+\left(l_{s} x u_{s}\right)+\left(l_{c} x u_{c}\right)+l_{o f}$

Dimana :

$l_{a} \quad$ : Redaman serat optik (attenuation loss) $\mathrm{dB} / \mathrm{Km}$

$l_{s} \quad$ : Redaman penyambungan (splice loss) $\mathrm{dB}$

$l_{c} \quad$ : Redaman konektor (connector loss) $\mathrm{dB}$

$l_{\text {of }} \quad$ : Redaman lainnya (other fiber loss) $\mathrm{dB}$

$L \quad$ : Jarak kabel serat optic (fiber length) $\mathrm{Km}$

$u_{s} \quad$ : Jumlah sambungan (unit)

$u_{c} \quad$ : Jumlah konektor (unit)

2. Redaman total sistem

$t_{l l}=t_{l f}+W D M(I L)+D C M(I L)-(G-N)+l_{o c}$

Dimana

WDM (IL) : WDM insertion loss $\mathrm{dB}$

DCM (IL) : DCM insertion loss $\mathrm{dB}$

Gain EDFA : Nilai penguatan dari EDFA dB

Noise ASE : Nilai noise dari EDFA dB

$l_{o c} \quad:$ Komponen redaman lainnya(other component loss) $\mathrm{dB}$

3. Redaman Akhir sistem

$t_{l l p}=t_{l l}+C D+P M D+P D L+n_{l}+e_{r}+t_{l l p}$

Dimana

$C D \quad$ : chromatic dispersion $\mathrm{dB}$

$P M D \quad:$ polarization mode dispersion $\mathrm{dB}$

PDL : polarization dependent loss $\mathrm{dB}$

$n_{l} \quad:$ nonlineardB

$e_{r} \quad:$ extinction ratio $\mathrm{dB}$

4. Cadangan untuk keamanan system

$s_{a} \quad:$ Cadangan untuk penuaan serat optik pada sistem (aging system) $\mathrm{dB}$

$c_{r} \quad:$ Cadangan untuk perbaikan kabel pada sistem(cable repair) $\mathrm{dB}$ 
5. Parameter input pada simulasi anggaran daya SKSO

Daya $: P_{t x}(\max ), P_{t x}(\min ), S_{r x}$

Redaman $: l_{a}, l_{s}, l_{c}, l_{o f}, L, u_{s}, u_{c}$

Redaman komponen lain : WDM (IL), DCM (IL), Gain EDFA (G), Noise EDFA (N), $l_{o c}$

Link loss penalty $\left(t_{l l p}\right): C D, P M D, P D L$, nonlinear $\left(n_{l}\right)$, extinction ratio $\left(e_{r}\right)$

Cadangan $: s_{a}, c_{r}$

6. Parameter ouput [4]

$$
\begin{aligned}
& P_{t r x}(\min )=P_{t x}(\min )-S_{r x} \\
& P_{r x}(\min )=P_{t x}(\min )-t_{l l} \\
& P_{r x}(\max )=P_{t x}(\max )-t_{l l} \\
& B_{o l}=P_{t r x}(\min )-t_{l l p} \\
& E_{o l}=B_{o l}-s_{a}-c_{r} \\
& L_{m a x}=L+\frac{\left(P_{r x}(\max )-S_{r x}\right)}{l_{a}} \\
& N_{-} E D F A=\frac{(G-N)}{P_{r x}(\max )-S_{r x}}
\end{aligned}
$$

Dimana :

$P_{t x}(\max ) \quad:$ Daya maksimum di pengirim (Maximum Transmit Power) $\mathrm{dBm}$

$P_{t x}(\min ) \quad$ : Daya minimum di pengirim (Minimum Transmit Power) $\mathrm{dBm}$

$S_{r x} \quad:$ Sensitivitas di penerima (Receiver sensitivity) $\mathrm{dBm}$

$P_{t r x}(\min ) \quad:$ Anggaran minimal pada transceiver $(\mathrm{dB})$

$P_{r x}(\min ) \quad:$ Daya minimum di penerima (minimum measurable receiver power) $\mathrm{dBm}$

$P_{r x}(\max ) \quad:$ Daya maksimum di penerima (maksimum measurable receiver power) $\mathrm{dBm}$

$B_{o l} \quad:$ Margin yang tersisa pada awal sistem kehidupan $(\mathrm{dB})$

$E_{\text {ol }} \quad:$ Margin yang tersisa pada akhir sistem kehidupan optik (dB)

$L_{\text {max }} \quad$ : Jarak maksimum $(\mathrm{Km})$

N_EDFA : Jumlah EDFA yang diperlukan (unit)

Pada Gambar 4 ditunjukkan diagram alir dari implementasi power link budget Sistem Komunikasi Serat Optik 


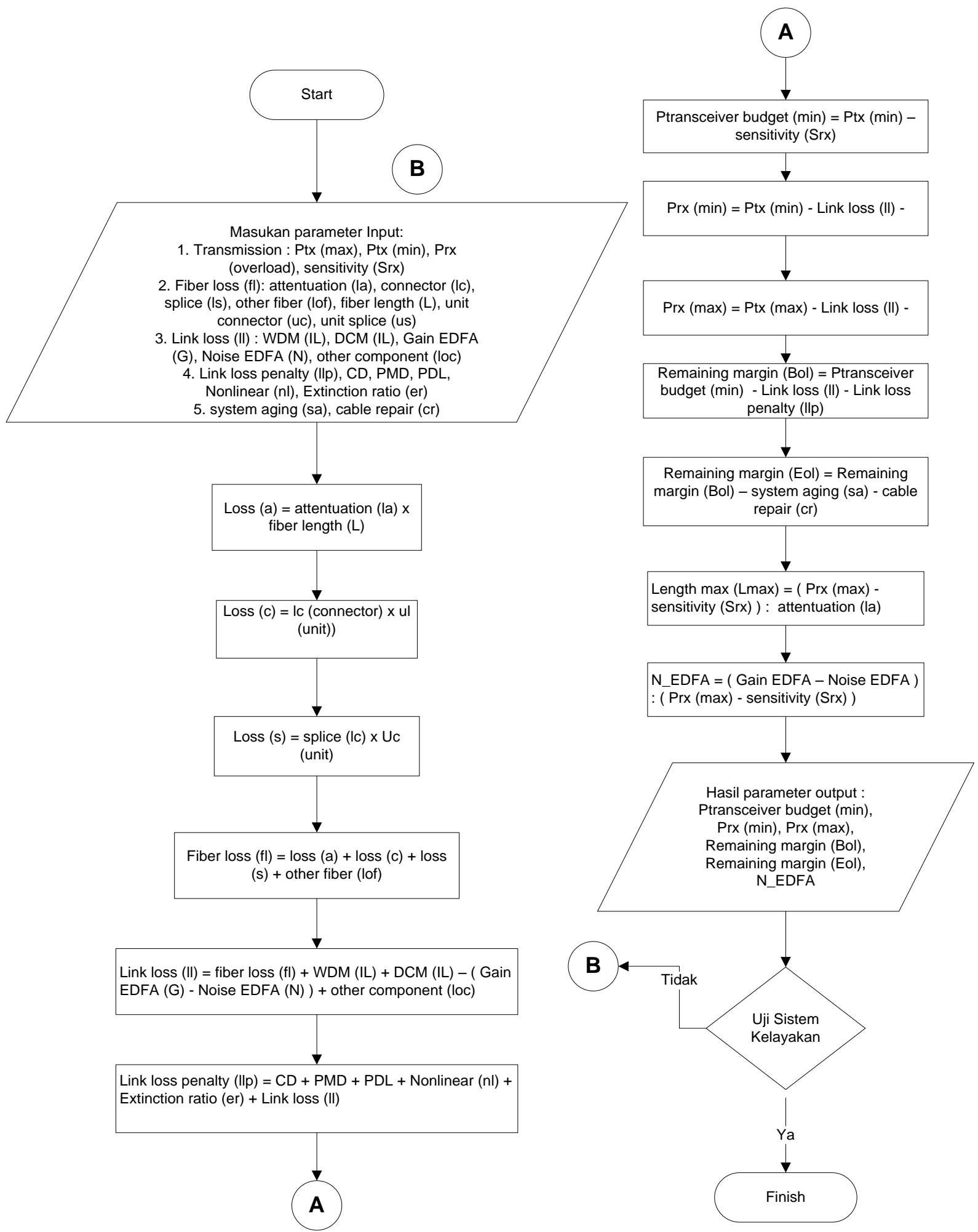

Gambar 4 Diagram Alir Power Link Budget

\section{HASIL dan PEMBAHASAN}

Simulasi perhitungan anggaran daya menggunakan software GUI Matlab 7.5 dan diimplementasikan untuk studi kasus jaringan Komunikasi Serat Optik untuk link BandungGarut. 
Tabel 1 menunjukkan nilai dari parameter Perencanaan Jaringan Sistem Komunikasi Serat Optik untuk link Bandung - garut

Tabel 1. Parameter Perencanaan Jaringan Sistem Komunikasi Serat Optik

\begin{tabular}{|c|c|}
\hline \multicolumn{2}{|c|}{ Data Teknis Perencanaan Link Bandung-Garut } \\
\hline \multicolumn{2}{|c|}{ 1. Parameter Desain } \\
\hline Bit rate/laju bit (BR) & 2.5 Gbps ( STM-16 ) \\
\hline Jarak total link (L) & $60 \mathrm{~km}$ \\
\hline BER ( Bit error rate) & $10^{-9}$ \\
\hline Format Modulasi & NRZ \\
\hline Dispersion Compensation Modul (DCM) & $\mathrm{P} / 30(\mathrm{~km})$ \\
\hline WDM ( DWDM $)$ & 4 channel \\
\hline Panjang kabel serat optik per roll & $4 \mathrm{~km} /$ roll \\
\hline \multicolumn{2}{|c|}{ 2. $\quad$ Komponen SKSO } \\
\hline \multicolumn{2}{|c|}{ 2.1 Serat Optik Single Mode : ITU-T G.652 } \\
\hline Atentuation loss (al) & $0,22 \mathrm{~dB} / \mathrm{km}$ \\
\hline Chormatic Dispersion (Tmat) SMF & $12 \mathrm{ps} / \mathrm{nm} . \mathrm{km}$ \\
\hline Intermodal Dispersion (Tmod) MMF & 0 \\
\hline \multicolumn{2}{|l|}{ 2.2 Optical interface } \\
\hline \multicolumn{2}{|l|}{ 2.2.1 Pengirim (transmitter) Laser } \\
\hline Maximum transmit power Ptx (max) & $5 \mathrm{dBm}$ \\
\hline Minimum transmit power Ptx (min) & $1 \mathrm{dBm}$ \\
\hline \multicolumn{2}{|l|}{ 2.2.1 Penerima (receiver) APD Detektor } \\
\hline Receiver sensitivity ( Srx) & $-25 \mathrm{dBm}$ \\
\hline Receiver overload power Prx (overload) & $-10 \mathrm{dBm}$ \\
\hline \multicolumn{2}{|l|}{ 2.2.1Komponen Tambahan Fiber dan } \\
\hline Connector loss (lc) & $0,75 \mathrm{~dB} /$ unit \\
\hline Splice loss (ls) 14 buah splice(sambungan) & $0,1 \mathrm{~dB} /$ unit \\
\hline WDM insertion loss (IL WDM) & $4 \mathrm{~dB}$ \\
\hline DCM insertion loss (IL DCM) & $2 \mathrm{~dB}$ \\
\hline Gain EDFA & $20 \mathrm{~dB}$ \\
\hline Noise ASE & $12 \mathrm{~dB}$ \\
\hline CD penalty & $2 \mathrm{~dB}$ \\
\hline PMD penalty & $1 \mathrm{~dB}$ \\
\hline PDL penalty & $1.25 \mathrm{~dB}$ \\
\hline Nonlinear penalties & $0.5 \mathrm{~dB}$ \\
\hline Extinction ratio penalty & $0.5 \mathrm{~dB}$ \\
\hline
\end{tabular}

Terdapat 2 pngujian yang dilakukan untuk menguji sistem yang telah diimplementasikan dimana nilai parameter input diambil dari tabel 1 .

1. Pengujian 1

Pengujian ini dilakukan untuk link bandung - garut tanpa EDFA 


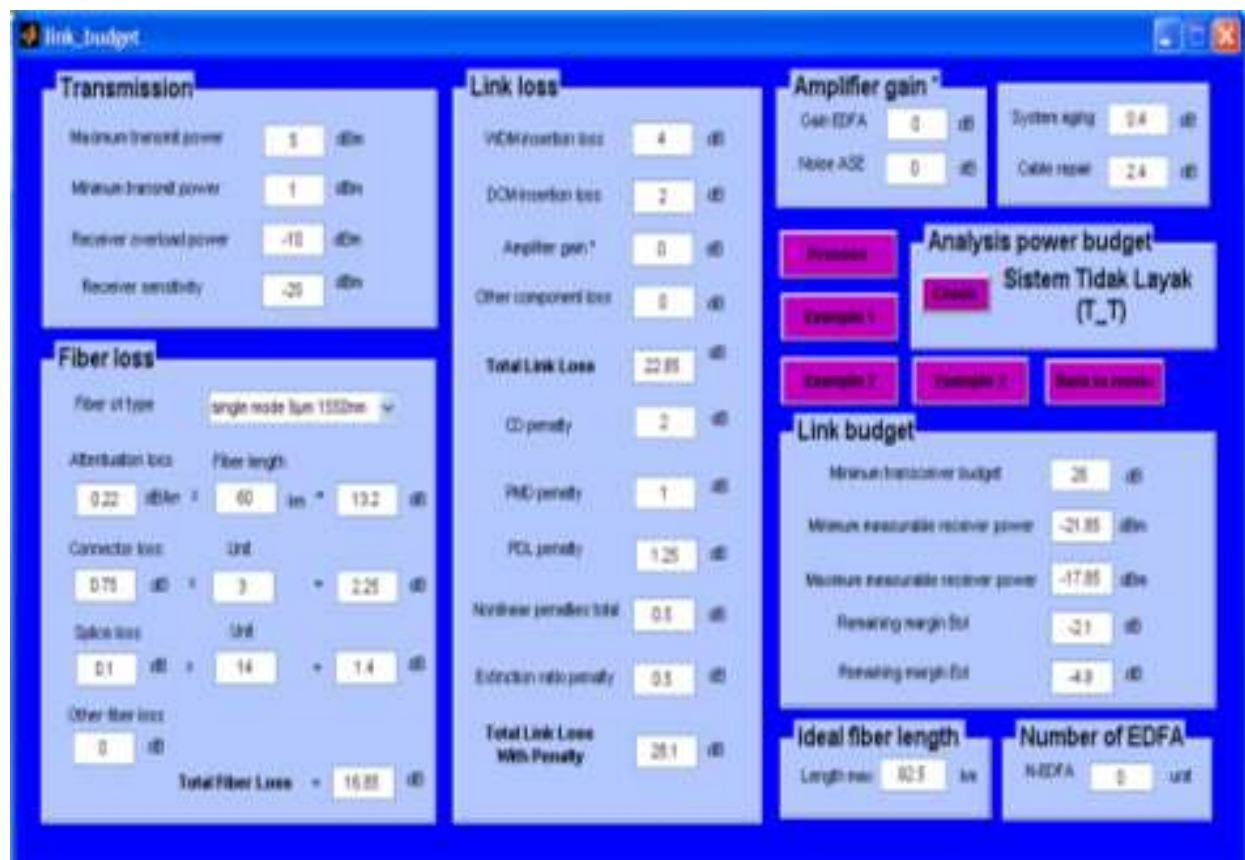

Gambar 4 Hasil Simulasi Perhitungan Tanpa Menggunakan Penguat Amplifier Gain (EDFA)

2. Pengujian 2

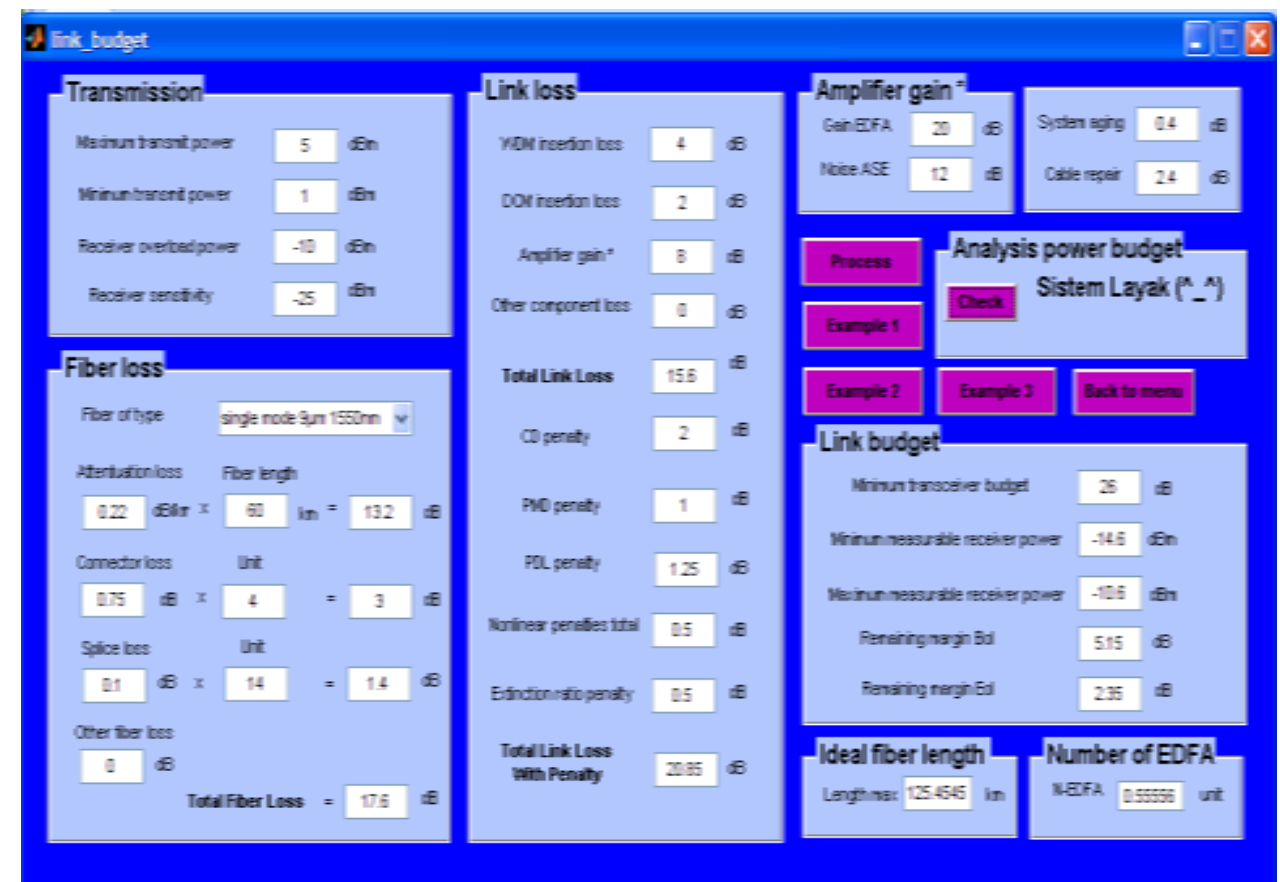

Gambar 5 Hasil Simulasi Perhitungan Menggunakan Penguat Amplifier Gain (EDFA)

Dari nilai parameter output hasil pengujian 1 dan 2 dapat dilakukan analisa untuk mengetahui kelayakan dari jaringan Sistem Komunikasi Serat Optik tersebut. Syarat yang dilakukan untuk melakukan analisa yaitu :

1. Nilai maximum measurable receiver power $\left(P_{r x} \max \right)$ lebih kecil dari receiver overload powe $r\left(P_{r x}\right)$, dari hasil yang didapat tanpa EDFA $(-17,85 \mathrm{dBm}<-10$ $\mathrm{dBm})$ dengan EDFA $(-10,6 \mathrm{dBm}<-10 \mathrm{dBm})$ dapat dinyatakan bahwa kedua pengujian sistem memenuhi persyaratan tersebut. 
2. Nilai remaining margin $B_{o l}>0$, dari hasil yang didapat tanpa $\operatorname{EDFA}(-2,1>0)$ dengan $\operatorname{EDFA}(5,15>0)$ dapat dinyatakan bahwa hanya pengujian sistem dengan EDFAyang memenuhi persyaratan tersebut.

3. Nilai remaining margin Eol $>0$, dari hasil yang didapattanpa $\operatorname{EDFA}(-4,9>0)$ dengan EDFA $(2,35>0)$ dapat dinyatakan bahwa hanya pengujian sistem dengan EDFA yang memenuhi persyaratan tersebut

Ketika persyaratan tersebut harus dipenuhi maka dapat dinyatakan bahwa SKSO Bandung-Garut dengan EDFA dinyatakan "layak", sedangkan SKSO Bandung-Garut tanpa EDFA dinyatakan "tidak layak".

\section{KESIMPULAN dan SARAN}

\subsection{KESIMPULAN}

Dari proses perencanaan dan perancangan simulasi perhitungan jaringan komunikasi serta hasil pengujian dan analisa serat optik ini ada beberapa hal yang dapat disimpulkan :

1. Pembuatan simulasi perhitungan anggaran daya sistem komunikasi serat optik ini berhasil dilakukan. Dengan menggunakan simulasi ini jumlah EDFA yang diperlukan pada suatu sistem komunikasi serat optik dapat deketahui dengan mudah.

2. Penggunaan penguat amplifier gain (EDFA) pada simulasi perhitungan optical power link budget pada saluran serat optik, akan mempengaruhi beberapa parameter output seperti jarak maksimum, Prx (max), Prx (min), Bol, dan Eol yang dapat membantu dalam sistem transmisi serat optik karena dapat memperkuat parameter daya output dan meminimalisir rugi-rugi sehingga sistem jaringan komunikasi serat optik tersebut dapat layak digunakan.

3. Pada perencanaan jaringan WDM link Bandung-Garut ini dapat diimplementasikan dilapangan, hal ini dapat dibuktikan dengan menggunakan 1 buah penguat EDFA sehingga nilai power link budget dapat menjangkau jarak tempuh sampai $125,45 \mathrm{~km}$ sedangkan jarak link Bandung-Garut sejauh $60 \mathrm{~km}$, Prx (max) sebesar -10,6 dBm, Prx (min) sebesar -14,6 dBm, Bol sebesar 5,15 dB dan Eol sebesar 2,35 dB, sehingga sistem ini layak digunakan.

\subsection{SARAN}

1. Simulasi perhitungan jaringan SKSOini dapat juga dirancang dengan software Visual Basic dan Java.

2. Simulasi perhitungan ini dapat digunakan dengan mengetahui parameter perencanaan jaringan komunikasi serat optik melalui studi kasus atau perencanaan sesuai kebutuhan yang diinginkan sehingga pengguna harus mengetahui standar-standar dari nilai parameter input yang dibutuhkan.

\section{Daftar Pustaka:}

[1] Chomycz, Bob. 2008.Planning Fiber Optic Networks. Enginering,Inc.

[2] Farrell, Gerald. 2008.Introduction to System Planning and Power Budgeting. DIT,Inc

[3] Ng Boon Chuan, A. Premadi, Mohammad Syuhaimi Ab-Rahman and K. Jumari. 2010. Optical power budget and cost estimation for Intelligent Fiber-To-theHome (i-FTTH). International Conference On Photonics 2010. Langkawi. Halaman. 1-5. 
[4] K. Cheung. 2015. The role of margin in link design and optimization. IEEE Aerospace Conference, Big Sky, MT. Halaman. 1-11.

[5] M. Bi, S. Xiao, H. He, J. Li, L. Liu and W. Hu. 2014. Power Budget Improved Symmetric 40-Gb/s Long Reach Stacked WDM-OFDM-PON System Based on Single Tunable Optical Filter. IEEE Photonics Journal, 6 (2). Halaman. 1-8. 